\title{
АКТУАЛЬНЫЕ ПРОБЛЕМЫ ПРАВОВОГО РЕГУЛИРОВАНИЯ ОРГАНИЗАЦИИ И ПРОВЕДЕНИЯ ЕДИНОГО ГОСУДАРСТВЕННОГО ЭКЗАМЕНА В РОССИЙСКОЙ ФЕДЕРАЦИИ
}

\section{CURRENT PROBLEMS IN THE LEGAL REGULATION OF THE ORGANIZATION OF UNIFORM STATE EXAM IN THE RUSSIAN FEDERATION}

A. Kuznetsov I. Vasilieva

Summary. Uniform State Exam (USE) is a key element of the unified system for assessing the quality of general education, Russian education project, unprecedented in the scale of technological innovation. It affects millions of schoolchildren and their parents. The experience gained in USE makes it possible to identify current problems and propose solutions. The aim of the article is to analyse the legal regulation of the organization USE as the main form of State certification of students and entrance tests to university education. Some conclusions are drawn from the practical experience of participating in the organization of USE and the university enrollment campaign.

Keywords: legal regulation, university education, enrollment campaign, State certification, Uniform State Exam (USE).
Кузнецов Антон Константинович

К.и.н., дочент, ФГБОУВО «Чувашский государственный университет имени И. Н. Ульянова»

(2. Чебоксары)

kuznetsov-ak@mail.ru

Васильева Жанна Сергеевна

К.и.н., доцент, ФГБОУ ВО «Чувашский государственный университет имени И. Н. Ульянова»

(2. Чебоксары)

kaf_advok@mail.ru

Аннотация. Единый государственный экзамен (ЕГЭ) представляет собой ключевой элемент единой системы оценки качества общего образования, беспрецедентный по масштабам внедрения технологических инноваций проект российского образования, затрагивающий интересы миллионов школьников и их родителей. Накопленный опыт проведения ЕГЭ позволяет выявить актуальные проблемы и предложить пути их решения. Настоящее исследование направлено на анализ правового регулирования организации и проведения ЕГЭ как основной формы государственной итоговой аттестации обучающихся и вступительных испытаний в вузы. Ряд выводов авторами сделан на основе практического опыта участия в организации ЕГЭ и приемной кампании вуза.

Ключевые слова: правовое регулирование, высшее образование, приемная кампания, государственная итоговая аттестация (ГИА), единый государственный экзамен (ЕГЭ).

калавриата и программам специалитета. Многие специалисты называю ЕГЭ экзаменами с высокими ставками.

Исследование систем оценки качества общего образования получило широкое освещение в работах отечественных и зарубежных специалистов: G. Psacharopoulos, G. Papakonstantinou, Su-Je Cho, C. Hudley, S. Lee, L. Barry, M. Kelly, J.L. Kobrin, E.J.Shaw, S. M. Barbuti, B. F. Patterson, K.D. Mattern, J.M. Rothstein, T. Khavenson, A. Solovyeva, R. M. Blackburn, J. Jarman, Х. Турбатинажод, P. A. Pathak, T. Sönmez, А.Д. Вербецкий, А.А. Фридман, Ю.Р. Вишневский, С.Ю.Вишневский, Д.Ю.Нархов, Д.Л. Константиновский, В.Г. Немировский, В.Я. Нечаев, И.А. Плохова, Ха Ван Хоанг, В.В. Фурсова и др. Проблемам доступности высшего образования в контексте ЕГЭ посвящены работы В.А.Болотова, С.С. Кравцова, М.М. Поташника, М.Л.Аграновича, А.Л. Лейбовича, Н.В. Колачевой, Н.Н. Кошелевой, А.Я. Пардала, Г.В. Андрущак, Т.В.Натхова и др. Вопросы организации и проведения ЕГЭ, 
формирования контрольных измерительных материалов нашли отражения в исследованиях С.С. Кравцова, А.А. Музаева, О.А. Решетниковой, Ю.С. Егоровой, И.К. Круглинского, Ю.С. Захир, Л.В. Караваевой, Г.С. Ковалевой и др.

Однако задача данной работы заключается в том, чтобы обозначить проблемы и представить предложения по дальнейшему совершенствованию правового обеспечения ЕГЭ с учетом многолетнего практического опыта организации и проведения ЕГЭ, а также приемной кампании вуза. В контексте необходимости дальнейшей модернизации, цифровизации данной оценочной процедуры, повышения прозрачности, объективности и общественного доверия вопросы правового регулирования также должны находится в поле зрения экспертов.

В соответствии с Федеральным законом от 29.12.2012 № 273-Ф3 «Об образовании в Российской Федерации» формы, порядок, сроки проведения государственной итоговой аттестации и продолжительность проведения экзаменов по каждому учебному предмету в рамках государственной итоговой аттестации по образовательным программам среднего общего образования определяются федеральным органом исполнительной власти, осуществляющим функции по выработке и реализации государственной политики и нормативно-правовому регулированию в сфере общего образования, совместно с федеральным органом исполнительной власти, осуществляющим функции по контролю и надзору в сфере образования [1].

Порядком проведения государственной итоговой аттестации по образовательным программам среднего общего образования, утвержденным приказом Министерства просвещения Российской Федерации и Федеральной службы по надзору в сфере образования и науки от 7 ноября 2018 г. № 190/1512 (зарегистрирован в Минюсте России 10 декабря 2018 г. № 52952) (далее Порядок проведения ГИА) определены формы проведения государственной итоговой аттестации по образовательным программам среднего общего образования (далее - ГИА), участники, требования к использованию средств обучения и воспитания, средств связи при проведении ГИА, требования, предъявляемые к лицам, привлекаемым к проведению ГИА, порядок проверки экзаменационных работ, порядок подачи и рассмотрения апелляций, изменения и (или) аннулирования результатов ГИА [2].

Обращает на себя внимание допуск к ГИА. В соответствии с частью 6 статьи 59 Федерального закона от 29 декабря 2012 г. № 273-Ф3 «Об образовании в Российской Федерации» к ГИА допускается обучающийся, не имеющий академической задолженности и в полном объеме выполнивший учебный план или индивидуальный учебный план, если иное не установлено порядком проведения ГИА по соответствующим образовательным программам [1]. В соответствии с пунктом 10 Порядка проведения ГИА к ГИА допускается обучающийся, не имеющий академической задолженности, в полном объеме выполнивший учебный план или индивидуальный учебный план (имеющий годовые отметки по всем учебным предметам учебного плана за каждый год обучения по образовательным программам среднего общего образования не ниже удовлетворительных), а также имеющий результат «зачет» за итоговое сочинение (изложение) [2].

Итоговое сочинение (изложение) как одно из условий допуска к ГИА выпускников текущего года было введено с 2014 года в соответствии с пунктами 26 и 2в Перечня поручений Президента Российской Федерации по итогам состоявшегося 2 октября 2013 г. заседания Совета при Президенте Российской Федерации по культуре и искусству № Пр-2699.

В 2018 году в штатный режим была введена особая форма допуска к ГИА для обучающихся по образовательным программам основного общего образования итоговое собеседование по русскому языку. Процедура и модель проведения итогового собеседования были разработаны в соответствии с распоряжением Правительства Российской Федерации от 09.04.2016 № 637-р «Об утверждении Концепции преподавания русского языка и литературы в Российской Федерации».

Итоговое сочинение (изложение) как условие допуска к ГИА для обучающихся по образовательным программам среднего общего образования и итоговое собеседование по русскому языку как условие допуска к ГИА для обучающихся по образовательным программам основного общего образования не являются частью ГИА. Считаем важным, чтобы формы допуска к ГИА были указаны в федеральном законе.

Предлагаем часть 6 статьи 59 Федерального закона от 29 декабря 2012 г. № 273-Ф3 «Об образовании в Российской Федерации» изложить в следующей редакции:

«6. К государственной итоговой аттестации по образовательным программам основного общего образования допускается обучающийся, не имеющий академической задолженности, в полном объеме выполнивший учебный план или индивидуальный учебный план и имеющий результат «зачет» за итоговое собеседование по русскому языку.

К государственной итоговой аттестации по образовательным программам среднего общего образования до- 
пускается обучающийся, не имеющий академической задолженности, в полном объеме выполнивший учебный план или индивидуальный учебный план и имеющий результат «зачет» за итоговое сочинение (изложение)».

Законодательное закрепление процедуры допуска ГИА позволит повысить значение данной формы оценки, а также ответственность органов исполнительной власти субъектов Российской Федерации, осуществляющих государственное управление в сфере образования, органов местного самоуправления, осуществляющих управление образованием, и образовательных организаций.

С момента проведения первых крупномасштабных апробаций ЕГЭ в 2001 году одним из основных неизменных принципов ЕГЭ являлось совмещение выпускниках (школьных) и вступительных (вузовских) экзаменов. В 2016 году произошло разделение ЕГЭ по математике на два уровня. В пункте 8 действующего Порядка проведения ГИА указано: «ЕГЭ по математике проводится по двум уровням:

- ЕГЭ, результаты которого признаются в качестве результатов ГИА общеобразовательными организациями и профессиональными образовательными организациями (далее - ЕГЭ по математике базового уровня);

- ЕГЭ, результаты которого признаются в качестве результатов ГИА общеобразовательными организациями и профессиональными образовательными организациями, а также в качестве результатов вступительных испытаний по математике при приеме на обучение по образовательным программам высшего образования -программам бакалавриата и программам специалитета в образовательные организации высшего образования (далее - ЕГЭ по математике профильного уровня)» [2].

Таким образом, ЕГЭ по математике базового уровня является только выпускным экзаменом, оценивающимся по пятибалльной шкале. Результаты данного экзамена не могут учитываться в качестве результатов вступительных испытаний при приеме в вуз. В соответствии с данными особенностями ЕГЭ по математике базового уровня соответствует другой форме ГИА: государственному выпускному экзамену (далее - ГВЭ).

В связи с тем, что ЕГЭ по математике базового уровня не соответствует принципу единого экзамена (совмещение вступительных и выпускных экзаменов), а также вызванными этим обстоятельством проблемами информирования в период приемной кампании, предлагается изменить форму данного экзамена на ГВЭ. Обучающиеся по образовательным программам среднего общего об- разования (выпускники текущего года) смогут по их желанию выбрать форму прохождения ГИА по математике (одному из обязательных учебных предметов ГИА): ЕГЭ по математике или ГВЭ по математике.

Такая схема может быть введена и для иностранного языка. В соответствии с Федеральным государственным образовательным стандартом среднего общего образования, утвержденным приказом Минобрнауки России от 17.05.2012 № 413 (зарегистрирован в Минюсте России 07.06.2012 № 24480) с 2022 года ГИА должна проводиться по трем обязательным учебным предметам: русский язык, математика и иностранный язык. «Обучающийся может самостоятельно выбрать уровень (базовый или углубленный), в соответствии с которым будет проводиться государственная итоговая аттестация в форме единого государственного экзамена» [3]. Предлагаем «уровень» сдачи экзамена по иностранным языкам заменить на «форму ГИА» (ЕГЭ по иностранному языку или ГВЭ по иностранному языку).

Одним из важнейших элементов ГИА являются федеральная информационная система обеспечения проведения государственной итоговой аттестации обучающихся, освоивших основные образовательные программы основного общего и среднего общего образования, и приема граждан в образовательные организации для получения среднего профессионального и высшего образования и региональные информационные системы обеспечения проведения государственной итоговой аттестации обучающихся, освоивших основные образовательные программы основного общего и среднего общего образования. Правила формирования и ведения данных систем утверждены постановлением Правительства Российской Федерации от 31 августа 2013 г. № 755. Необходимо отметить, что на сегодня ЕГЭ является одним из самых высокотехнологических экзаменов в мире.

Тем не менее, одной из проблем цифровизации экзаменов является соблюдение требований обработки персональных данных. Ежегодно при написании заявления на участие в ГИА определенная доля выпускников (их родителей или законных представителей) не дает своего согласия на обработку персональных данных. В соответствии с письмом Федеральной службы по надзору в сфере образования и науки от 17.03.2015 № 02-91 для обучающихся, отказавшихся дать согласие на обработку персональных данных, ГИА может быть организована без внесения их персональных данных в информационные системы. Подготовка, проведение и обработка результатов ГИА для таких участников ГИА возложена на органы исполнительной власти субъектов Российской Федерации, осуществляющих государственное управление в сфере образования. 
Так, например, решением государственной экзаменационной комиссии субъекта Российской Федерации по организации и проведению ГИА для участников ГИА, отказавшихся дать согласие на обработку персональных данных, определяется пункт проведения, аудитория и рабочее место сдачи ГИА. Однако необходимо отметить, что в соответствии с пунктом 62 Порядка проведения ГИА «за один день до проведения экзамена по соответствующему учебному предмету региональный центр обработки информации осуществляет автоматизированное распределение участников экзаменов и организаторов по аудиториям» [2]. Таким образом, Порядок проведения ГИА не предусматривает иной (неавтоматизированной) процедуры распределения участников ГИА. К тому же в соответствии с пунктом 4 статьи 19.30 Кодекса Российской Федерации об административных правонарушениях нарушение указанного порядка влечет наложение административного штрафа на граждан в размере от трех тысяч до пяти тысяч рублей; на должностных лиц - от двадцати тысяч до сорока тысяч рублей; на юридических лиц - от пятидесяти тысяч до двухсот тысяч рублей [4].

Считаем необходимым внести соответствующие нормы в Порядок проведения ГИА в части регулирования правоотношений участников ГИА, отказавшихся дать согласие на обработку персональных данных.

Важно отметить необходимость гармонизации правового поля в части внедрения новых информационных технологий. В 2020 году запланированы применение новых мер информационной безопасности, профилактики нарушений порядка проведения экзаменов: технология поведенческого анализа на основе нейронных сетей; идентификация личности по видеокамерам; внедрение технологии искусственного интеллекта и др.

Трудно согласиться с позицией Минпросвещения России по вопросу повторного прохождения ГИА. В письме Департамента государственной политики в сфере оценки качества общего образования Минпросвещения России от 29 января 2020 г. № 04-123 указано, что в соответствии с пунктом 95 Порядка проведения ГИА, обучающимся, не прошедшим ГИА в текущем году в связи с получением неудовлетворительного результата по одному из учебных предметов, предоставляется право пройти экзамены по соответствующим учебным предметам в следующем году. Лица, не прошедшие ГИА в прошлом году в связи с получением неудовлетворительного результата по одному из обязательных учебных предметов, не относятся к категории лиц, освоивших образовательные программы среднего общего образования в предыдущие годы, имеющих право на участие в ЕГЭ, при наличии у них действующих результатов (пункт 13 Порядка проведения ГИА), так как не имеют соответствующего документа об образовании, подтверждающего освоения указанных программ.

Следовательно, отмечает Департамент государственной политики в сфере оценки качества общего образования Минпросвещения России, они не могут: выбрать один или несколько предметов (из списка предметов по выбору), на сдачу экзаменов по которым не регистрировались в прошлом году; а также выбрать для сдачи предмет, экзамен, который уже сдан в прошлом году, в целях улучшения результата по нему.

Таким образом, выпускники, не прошедшие ГИА, могут принять участие в ГИА в следующем году только по учебному предмету (предметам), по которому получен неудовлетворительный результат. Причины, по которым данные участники ГИА не могут принимать участие в ЕГЭ, не понятны. Они имеют допуск к ГИА (результат «зачет» за итоговое сочинение (изложение)) и не отличаются от выпускников, участвующих в ГИА впервые. Однако данная категория выпускников, в случае повторного успешного участия в ГИА, может быть лишена конституционного права на получение высшего образования.

Считаем важным внести изменения в пункт 13 Порядка проведения ГИА, предоставив право участникам ГИА, не прошедшим ГИА в прошлые годы, сдачи ЕГЭ по предметам по выбору. Лица, не прошедшие ГИА в прошлые годы, но получившие документ об образовании в текущем году, должны иметь возможность на поступление в вуз.

Обращает на себя внимание еще одна категория участников ЕГЭ - выпускники прошлых лет. В действовавшем до 07.03.2014 Порядке приема граждан в образовательные учреждения высшего профессионального образования, утвержденном приказом Минобрнауки России от 28.12.2011 № 2895 (зарегистрирован в Минюсте России 24.01.2012 № 23011), содержалась норма, согласно которой лица, имевшие среднее (полное) общее образование, полученное до 1 января 2009 г., имели право поступать в вуз на основании результатов внутренних вступительных испытаний. На сегодняшний день такая норма отсутствует. Выпускники прошлых лет (не имеющие среднего профессионального или высшего образования) для поступления в вуз должны сдавать ЕГЭ (в том числе и те выпускники, которые получили аттестат в советский период).

Актуальность проблемы вызвана необходимостью непрерывного образования (life-long learning education). Для выпускников, которые не сдавали ЕГЭ в школе (получили аттестат о среднем общем образовании по другим правилам), поступление в вуз по результатам ЕГЭ становится серьезным испытанием (проблемы информированности о процедуре, тестовая искушенность и т.д.). 
Считаем, что таким выпускникам необходимо предоставить возможность поступления в вуз по внутренним вступительным испытаниям. Предлагаем также расширить категорию данных выпускников, включив не только лиц, получивших аттестат о среднем (полном) общем образовании до 1 января 2009 г. (т.е. до введения ЕГЭ в штатный режим), но и получивших данный документ об образовании до 1 сентября 2013 г. (т.е. до вступления в силу действующего Федерального закона от 29.12.2012 № 273-Ф3 «Об образовании в Российской Федерации»).

Таким образом, предлагаем внести изменение в часть 6 статьи 70 Федерального закона от 29.12.2012 №273-Ф3 «Об образовании в Российской Федерации». Предоставить право выпускникам прошлых лет, получившим аттестат о среднем общем образовании до 1 сентября 2013 г., поступать в вузы по результатам внутренних вступительных испытаний.

В силу своей масштабности и значимости ЕГЭ оказывает колоссальное влияние на всю систему российского образования и, безусловно, нуждается в развитии, поВышении эффективности. В данной работе предпринята попытка на основе практического опыта организации и проведения ЕГЭ, а также участия в приемной кампании вуза представить предложения по совершенствованию правового регулирования основной формы ГИА, расширению доступности высшего образования:

1. В Федеральном законе от 29.12.2012 № 273-Ф3 «Об образовании в Российской Федерации» закрепить формы допуска к государственной итоговой аттестации (итоговое сочинение (изложение) для обучающихся по образовательным программам среднего общего образования и итоговое собеседование по русскому языку для обучающихся по образовательным программам основного общего образования).
2. ЕГЭ по математике базового уровня заменить на иную форму ГИА - ГВЭ по математике (в связи с тем, что результаты данного экзамена не могут учитываться в качестве результатов вступительных испытаний при приеме в вуз). Распространить данное положение на вводимый с 2022 года обязательный ЕГЭ по иностранным языкам.

3. Привести нормативные правовые акты в соответствие с внедряемыми новыми информационными технологиями: технология поведенческого анализа на основе нейронных сетей; идентификация личности по видеокамерам; технология искусственного интеллекта и др.

4. В Порядке проведения ГИА закрепить процедуру проведения экзаменов для лиц, отказавшихся дать согласие на обработку персональных данных, в Порядке приема на обучение по образовательным программам высшего образования - программам бакалавриата, программам специалитета, программам магистратуры, утвержденном приказом Минобрнауки России от 14.10.2015 № 1147,- процедуру получения результатов ЕГЭ таких участников ЕГЭ приемными комиссиями вузов.

5. Разрешить выпускникам прошлых лет, не прошедшим ГИА, сдавать не только экзамен (экзамены), по которому получен неудовлетворительный результат, но и ЕГЭ по предметам по выбору.

6. Предоставить право выпускникам прошлых лет, получивших аттестат о среднем общем образовании до 1 сентября 2013 года, поступать в вузы по результатам внутренних вступительных испытаний.

7. Рассмотреть возможность создания независимых центров оценки качества образования для круглогодичного проведения ЕГЭ, а также участия в ЕГЭ несколько раз в год.

\section{ЛИТЕРАТУРА}

1. 06 образовании в Российской Федерации: Федеральный закон от 29.12.2012 № 273-Ф3 // «Российская газета», № 303, 31.12.2012, официальный интернет-портал правовой информации http://www.pravo.gov.ru, 01.03.2020.

2. 06 утверждении Порядка проведения государственной итоговой аттестации по образовательным программам среднего общего образования: Приказ Минпросвещения России и Рособрнадзора от 07.11.2018 № 1512/190 // официальный интернет-портал правовой информации http://www.pravo.gov.ru, 11.12.2018.

3. Об утверждении федерального государственного образовательного стандарта среднего общего образования: Приказ Минобрнауки России от 17.05 .2012 № 413 // «Российская газета», № 139, 21.06.2012, официальный интернет-портал правовой информации http://www.pravo.gov.ru, 27.07.2017.

4. К Кодекс Российской Федерации об административных правонарушениях от 30.12.2001 № 195-Ф3 // «Российская газета», № 256, 31.12.2001, 0фициальный интернет-портал правовой информации http://www.pravo.gov.ru, 18.03.2020. 